\title{
Translation of Arabic Ecological Terms: An Eco-Cultural Approach
}

\author{
Ahmad Mustafa Halimah* \\ Department of English Language, College of Arts, King Faisal University, Kingdom of Saudi Arabia
}

Corresponding Author: Ahmad Mustafa Halimah, E-mail: ahalimah@kfu.edu.sa

\section{ARTICLE INFO}

Article history

Received: February 02, 2018

Accepted: April 21, 2018

Published: April 30, 2018

Volume: 6 Issue: 2

Conflicts of interest: None

Funding: None

\begin{abstract}
Unlike most translations which are carried out within the Indo-European language-family and culture, the translation of Arabic language and culture into English language and culture tends to cause serious problems for translators. This paper is an attempt to examine the problems and difficulties in translating Arabic ecological terms of literary and religious texts using Peter Newmark's (1988) ecological categorizations of 'Fauna', Flora', and other 'Geographical features' in conceptualised and contextualised examples as parameters for discussion and analysis. Results of the discussion and analysis of the samples used in this paper have highlighted the importance of attending to ecological issues in translation and the need for an eco-cultural approach to be used for solving such problems. Some suggestions and recommendations have been made to help translators adjust their translation methods to fit the Arabic eco-cultural context as well as those who are interested in carrying out further research in this field.
\end{abstract}

\section{Keywords: \\ Translation, \\ Culture, \\ Ecology, \\ Fauna, \\ Flora, \\ Arabic Terms, \\ Problem, \\ Solution}

\section{INTRODUCTION}

When it comes to translating ecological terms in literary and religious contexts, the translation of Arabic language and culture into English language and culture has a difficulty and heap of problems that most translations carried out within the Indo-European language-family and culture are scarce of. One reason for this could be attributed to their tendency to use 'literalness and avoid foreign words' in their translation (Nida, 1945:195).

Furthermore, where there is territory distance between one language and another, there is ecological variation and where there is an ecological focus, there is a translation problem due to the 'cultural gap or distance between the source and target languages' (Newmark, 1988:94). This kind of extreme ecological variation between Arabic and English tends to make translators pay attention to the ecological feature and 'overlook the different cultural significance involved' (Nida, 1945:198).

Issues of Arabic-English-Arabic translation problems are long standing and well addressed in cross-linguistic and cross-cultural research literature (Abdul-Raof, 2005,
Al-Shabab, 2008, Ghazala, 2014). Unfortunately, the issue of translating ecological terms in literary and religious contexts has not been researched yet. The main objective of this study is two fold: to examine the problems and difficulties in translating Arabic ecological terms that are facing the translators of literary and religious texts by using Peter Newmark's (1988) ecological categorizations of 'Fauna', 'Flora' and other 'environmental features' and to argue for an eco-cultural translation method that would fit the Arabic eco-cultural contexts and the natives' perceptions. Achieving such objectives would then bring forth the introduction of a fresh new approach to the cultivated art of eco-cultural translation that would contribute to helping translators overcome the translation difficulties and problems in this field as well as those in other text-types with little adaptation.

\section{THEORTICAL CONSIDERATIONS}

According to Vinokurov et al (2007:42), ecology can be defined as "the study of the interactions of organisms to their physical environment and to one another". In other words, it is the study of the relations between fauna and flora and 
their physical surroundings, be it their physical natural world or the people around them. For Peter Newmark (1988:95), ecology covers 'fauna, flora, winds, plains, hills; 'honeysuckles', 'downs', 'plateau'. These eco-cultural categories tend to cause serious concerns for translators and therefore will be used in the analysis and discussion of the data in this article.

In his seminal article "Linguistics and Ethnology in Translation", Eugene Nida (1945:194) underlines the relationship between linguistics and ethnology pointing out that "the person who is engaged in translating from one language into another ought to be constantly aware of the contrast in the entire range of culture represented by the two languages". He looks at translation problems as problems of equivalence in terms of cultural aspects as in 'ecology', 'material culture', 'social culture', 'religious culture', and 'linguistic culture'. This current study, however, will be mainly concerned with the translation of the cultural aspect of 'ecology' between Arabic and English where translators tend to make errors in translating ecological terms because they use 'literalness' and 'avoid using foreign words' in their translation (Ibid: 195). Furthermore, it will argue for translation methods that would fit the Arabic eco-cultural context and the natives' perceptions rather than those already in practice.

In their article, "Translation as an Ecological Tool for Instrument Development", Vinokurov et al (2007) explored the cross-cultural issues in the translation of a survey instrument which involved Macro International's evaluation of the Department of State's International Visitor Leadership Program (IVLP) in Russia and three other countries of the Commonwealth of Independent States (CIS); Ukraine, Kazakhstan, and Georgia. They emphasised the contextual factors that influenced translation and the necessity of adjusting translation methods to suit a certain cultural setting.

In response to calls for standardising the definitions of ecological terms in sciences in general, Karen Hodges (2008:37) argues that misunderstanding and misinterpreting an ecological term should not be attributed to the term itself being "polysemous but rather to the lack of contextual or explicit clues that identify which meaning is intended". This argument in part seems to be in line with the argument held in this paper where understanding an ecological term whether it belongs to a fauna, flora, or any other ecological category is mainly determined by its contextual setting and by how the natives tend to perceive and interpret the term in question.

Zakamulina, M.N \& Lutfullina, G.F, (2013:3) conducted a translation task-based study of Russian first-year engineering students where they asked students to translate ecological compound terms from English into Russian. These terms were taken from their basic science textbook and the tasks were merely to find equivalents in Russian. Based on such experiment they suggested a structural approach to translating ecological scientific compound terms and teaching translation skills. What they suggested as an approach of translating compound terms (i.e. to translate the last word which is the main word of the combination and then translate all other words as dependent of the main word and qualifying it) could be valid but limited to the translation of isolated terms or sentences. Furthermore, a good bilingual scientific dictionary would be sufficient for this purpose. When it comes to translating ecological terms in a literary or religious context, for example, the problem becomes more severe because the meaning and equivalent cannot be achieved in isolation or in a mere bilingual dictionary but rather in an eco-cultural context as will be discussed below.

Having made those references, and based on the theoretical consideration mentioned above, I am inclined to adopt an eco-cultural approach that emphasises the Arabic language and culture in translating Arabic ecological terms. This approach aims to carry out both the exact denotative meaning as well as the eco-cultural connotations of the Arabic ecological terms into the translation with a literary or religious context. In other words, understanding an ecological term, whether it belongs to a fauna, flora or any other ecological category, is mainly determined by its eco-cultural contextual setting and by how the natives tend to perceive and interpret the term in question. This same understanding and perception should be reflected in translation as much as possible. Newmark's (1988) ecological categorizations of 'Fauna", 'Flora', and other 'Geographical features' will be used in the analysis and discussion of the data and the argument for translation methods that would fit the Arabic eco-cultural contexts and the natives' perceptions.

\section{Research Question}

The following question was formed to investigate the problems and difficulties in translating Arabic ecological terms into English:

Does the translation of Arabic Ecological Terms into English in literary and religious texts cause problems and difficulties for translators? If it does, what are the issues caused and how can they be addressed?

\section{METHODOLOGY}

The aim of this study was to examine the problems and difficulties in translating Arabic ecological terms into English and make an attempt to suggest an eco-cultural approach to address such issues.

To achieve this aim, examples of fauna, flora, and geographical features were drawn from literary and religious texts mainly from the Quran, Prophetic Hadeeths and poetry. It is worth mentioning that throughout this study it has been assumed that these translations have been made by linguistically well-trained and experienced translators. The value of the data used in this study is of a special significance because the Quran and the Prophetic Hadeeths have been translated into many different languages and there is an increasing number of translations of both of them available in English (see Halimah, 2014 and 2017). Furthermore, the eco-cultural elements mentioned in these two significant sources tend to be somewhat different from those in the present Western eco-culture which is mainly Bible specific (Nida, 1945).

To see how and why translators tend to find Arabic ecological terms problematic and difficult to translate into En- 
glish and fail to use appropriate translation procedures, Newmark's (1988) ecological categorizations of 'Fauna', 'Flora', and 'Geographical features' were used in conceptualised and contextualised examples as parameters. Then, a corpus of fifteen ecological terms was randomly drawn from several translations of the Quran, Prophetic Hadeeths and poetry: 5 fauna terms, 5 flora terms and 5 geographical terms. Due to a lack of space, and for the sake of convenience, three fauna examples, three Flora examples and only two examples from the geographical features category were analysed and discussed.

It is not the purpose of this study to show that translators of Arabic ecology tend to fail at achieving eco-cultural equivalence in their translations but rather that these translators seem to lack the proper Arabic eco-cultural background and use inappropriate procedures such as 'literalness' in translating Arabic ecological terms into English.

\section{THE TRANSLATION OF ARABIC ECOLOGICAL TERMS}

Language, culture and translation are quite interrelated and essential in understanding "the source text and in representing the meaning in a target language-culture", especially in religious texts (Nida, 2001, Page I). In other words, there is hardly any religious text that isn't culture-specific or without some kind of cultural focus in it. Therefore, as Newmark (1988:94) puts it, "when there is a cultural focus, there is a translation problem due to the cultural 'gap' or 'distance' between the SL and TL". Based on these assumptions, and due to a lack of space, a few examples from poetry, the Quran and Prophetic Hadeeths are given and discussed mainly from an eco-cultural perspective as follows:

\section{The Translation of Fauna Ecological Terms}

A dictionary meaning of 'fauna' is the 'animals of a particular region, habitat, or geological period'. In other words, it is the animals of a particular environment, be it the Arabian Peninsula, Europe, North America or any other particular land in the world, which has its own specific fauna. Furthermore, there tends to be a strong relationship between the environment and its animals as well as between the animals and people living in the particular region or land. This triangle relationship between animals, environment and people is clearly manifested in the people's culture-specific reactions, perceptions and attitudes towards animals as demonstrated below.

With regard to translation, particularly Arabic-English translation, this triangle relationship seems to be quite complicated, problematic and a cause of concern for translators because the Arabic fauna and the English fauna tend to belong to two different ecological value-systems.

Fauna Example (1): The translation of 'faunaness' in the term: "جمل/jamal/camel"

When the term "جمل/jamal/camel" is mentioned in context or non-context, it carries with it an amalgamation of en-vironmental, social, cultural and even religious associations and connotations, such as 'the ship of the desert', 'symbol of national pride', 'image of love and compassion', 'sacred animal', being praised in the Quran and by Prophet Muhammad (䌊) respectively.

Thus, due to the camel's environmentally unique habitat, social prestige and religious significance in the Arab world in general and the Arabian peninsula in particular, translating the faunaness of the term 'جمل/jamal/camel' into English tends to be one of the most difficult ecological problems that translators encounter, especially in the poetry genre. In other words, the transfer of the image of 'love' between two lovers' animals in the example below is a manifestation of how strong, effective and positively unusual in the poet's culture it is and how difficult and problematic it is to translate the image and tone of the original poem into the TL reader's culture. This is due to the languages and cultures belonging to two completely different ecologies, an Arabic scorching hot eco-culture and an English cold and windy eco-culture. The problem is also aggravated by the lack of a clear distinction between a male and a female camel in the language and culture of the target readers. There is also not only just a great environmental distance between the languages and their cultures but also a gap between readers' perceptions and experiences be they linguistic, literary, cultural or even spiritual.

By looking at the following line of Arabic poetry by al-Munkhil al-Yashkri (b. 584), where the poet compares his love to his beloved with the love of their animals, we realize how seriously problematic it can be to translate from Arabic into English.

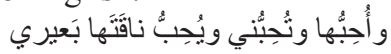

At first glance, as one of my postgraduate students said, "It's a piece of cake", which rings true for the first part of the line that could be easily translated as "I love her, and she loves me". A problem, however, then arises from the difficulty in understanding the second part of the verse due to an unusual and ambiguous grammatical structure where the poet swaps the position of the subject (my he-camel/baeer/بَعيري with that of the object (her she-camel/naqataha/ناقَتَّis). This problem is then followed up by another which could be taken as more complicated due to its eco-culture-specific nature.

Although the word (naqataha/ناقَتَها) may be translated into "her she-camel", the image would still seem peculiar to the readers of the TL since they are not familiar with this particular distinction. This unfamiliarity of the English language readers with the distinction and truth-value of the animal may lead to either misunderstanding the translated text or depreciating the source text. The following possible translations of the above line of poetry are just examples of how serious and problematic the translation of an eco-cultural term like that of the camel could be.

A. I love her and she loves me and my camel loves her camel

B. I love her and she loves me and my he-camel loves her she-camel

C. I love her and she loves me and my male-camel loves her female-camel

D. I fancy her and she fancies me and my horse fancies her mare 
E. I fancy her and she fancies me and my dog fancies her bitch

F. I love her and she loves me and my pig loves her sow

G. Love me love my dog

As a monolingual and monoculture English reader, you might opt to what appeals to your own eco-cultural perception of this camel 'love' image or metaphor in the poem which could be any of the above options except A, B, or C. As a bilingual and bicultural reader, however, you are bound to opt for the translations $\mathrm{A}, \mathrm{B}$ or $\mathrm{C}$ because they meet your bi-eco-cultural value-systems, especially if you would like to emphasise the Arabic Eco-cultural value system in your translation.

Out of the list of the above examples, the most appropriate translation is actually $\mathrm{B}$ because it is the most accurate and shortens the environmental distance between SL and TL as well as provides the reader with new experiences of the 'faunaness' in the term: "jamal/جمل/camel" be they linguistic, literary, cultural or even emotional. Futhermore, the Arabic Eco-cultural value system is emphasised in this particular translation more than in $\mathrm{A}$ or $\mathrm{C}$ and is on more of a personal level than example $\mathrm{C}$.

Fauna Example (2): The translation of 'faunaness' in the term: 'boomah/بومة/owl'

When translating, it is important to take into account the possibility of an allusion, that is common knowledge in the cultural environment of the source language, being in the text. The owl, for example, is normally used in Arabic to refer to a bad omen and bad luck whereas in the English culture it is not necessarily a bad omen but rather a symbol of wisdom and sometimes love, as exemplified by Figure 1 below:

The above example shows that people's attitudes towards animals differ from one society to another. Each society has its own ecological value-system which is reflected in the writings of its people. This difference between society value-systems gives rise to serious problems in Arabic-English-Arabic translation as illustrated above; thus, ecological translators should be aware of such potential issues.

Let us look at one more example and see how culture-specific words tend to give rise to the misunderstanding of the translated text as well as depreciation of the source text because of bad translation. Looking at the following line, we can still say that no matter how skilful the translator may be, he or she still falls victim to the historical, social and eco-cultural associations and connotations attached to poetry. In Arthur Wormhoudt's (1978:503) translation of Diwan al-Mutanabbi below, ambiguity and mistakes arise from the gaps in the translator's eco-cultural knowledge of animals such as owls and rakham. (Note 1)

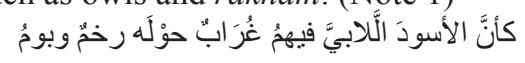

As if the Nubian blacks were crows around them vultures and owls

In addition to the grammatical mistake made in pluralising the singular word الأسود 'the black' into 'blacks', Wormhoudt's historical and eco-cultural knowledge of the 'owl' is quite poor. His translation distorts the meaning and does not convey the same message as the Arabic version because the main object of al-Mutanabbi's satire 'هجاء' in the line is Kafur al-Ikhsheedi, the black ruler of Egypt, who was compared to a crow surrounded by 'rakhams' and owls. The former indicates that the people around him were not only weak, dependent and lazy but also acted as parasites do just like the weak, dependent, lazy, parasitic 'rakham' of a falcon. Furthermore, when the 'owl' is used in Arabic, it is generally used to refer to a bad omen and bad luck whereas in the English eco-culture it is taken rather as a symbol of wisdom and sometimes love, as exemplified by (Figure 1 below).

This unfamiliarity of the English language readers with the distinction and truth-value of the 'owl' may lead to them either misunderstanding the translated text or depreciating the source text. The following possible translations of the above poetic line are just examples of how serious and problematic the translation of an eco-cultural term like that of the owl could be:

A. As if the Nubian black among them was a crow among 'rakhams' and owls

B. As if the black ruler of them all was a crow surrounded by 'rakhams' and owls

C. As if the Nubian black was a crow surrounded by foxes and black cats

D. As if the Nubian black was a crow surrounded by vultures and hyenas

Like example No.1above, monolingual and mono-eco-culture English language readers would accept linguistically and eco-culturally versions of $\mathrm{C}$ and $\mathrm{D}$ but not $\mathrm{A}$ and $\mathrm{B}$ because in $\mathrm{A}$ and $\mathrm{B}$ versions the combination of 'rakhams' and owls is not acceptable to them as 'rakhams' is a symbol of weakness and laziness whereas the owl is a symbol of mainly wisdom and sometimes love. As for a bilingual and bicultural reader, however, the versions A and B are quite acceptable because the terms 'rakhams' and owls collocate with one another in the bi-eco-cultural value-systems of the Arabic/English readers and emphasise the Arabic Eco-cultural value system in the translation.

The most appropriate translation for the above example would have to be A because it achieves appropriate collocation according to the Arabic eco-culture and introduces a new perception and conception of the 'faunaness' of the term 'owl'into the English Fauna system. Option B is ruled out as it is not linguistically accurate.

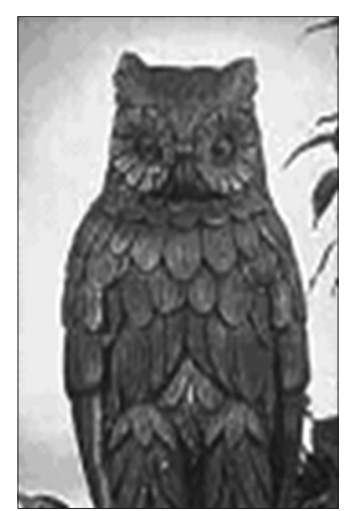

Figure 1: This is Prince Andrew's gift to his lovebird Sarah Ferguson......an owl that proves she's a "night bird and a real hoot". Guess where she keeps her love token. The Star, March 19, 1986 
Fauna Example (3): The translation of 'faunaness' in the term: deek/ديك/rooster

Like any other animal, roosters have their own habitat and tend to signify different things to different people depending on the environment they are found in. Although chickens can be found on almost every continent except Antarctica, they tend to mainly live in mild and warm climates. Roosters which live, for example, in Turkey and the Middle East, mainly in the Arab world, tend to have eco-cultural associations and connotations different from those living in farms in Europe in general and Britain in particular. It was reported that Nasr bin Sayyar Allaythee (b.666 and d. 748) said: "The elite Turks used to say to their great leader: You must possess ten animal qualities in yourself: the generosity of the rooster, the motherliness of the hen, the heart of the lion, the steadfastness of the boar, the cunningness of the fox, the deceitfulness of the wolf, the patience of the dog towards his wounds, the caution of the raven, the protecting character of the crane and the guidance of the pigeon". (Aljahiz, 2008; Vol.2, P.438)

Furthermore, the rooster is religiously sacred and ecologically highly regarded by Muslims because Muhammad the Messenger of Allah (矣) said: "Don't curse the rooster for it is he who awakens you for Dawn prayer",(Bukhari) whereas in "Christianity the Rooster is noted for crowing three times after Peter denied Christ. As such, it became a symbol for Christ's passion. Later, the Rooster would signify the repentance of the saint and religious vigilance as well as resurrection" (Note 2). It is also worth noting that in the Indian eco-cultural value-system the rooster tends to signify "death" as in the following proverb "Beware of the bark of a dog or 'crow' of a cock at night, for they signify death' (Note 3).

The following table shows a simple comparison between the symbols of the rooster generally perceived by people of the European ecological value-system and those perceived by people of the Middle Eastern one based on examples from the literature of both systems.

\begin{tabular}{ll}
\hline $\begin{array}{l}\text { European ecological } \\
\text { value-system of the } \\
\text { rooster.(Associations and } \\
\text { connotations) }\end{array}$ & $\begin{array}{l}\text { Middle eastern } \\
\text { ecological value-system } \\
\text { of the rooster. } \\
\text { (Associations \& } \\
\text { connotations) }\end{array}$ \\
\hline 1. Pride/honesty/courage/ & 1. Not applicable \\
arrogance/strength/ & 2. Vigilance (he awakens \\
2. Vigilance/watchfulness & for dawn prayer) \\
3. Flamboyance. & 3. Flamboyance (he is \\
likened to a peacock) & 4. Generosity and kindness \\
& 5. Clarity (of his eyes) \\
6. Quickness (of his \\
actions/cock pecking) \\
7. A lot of love making to \\
his hens \\
8. Angelic crowing (as in \\
when you hear the cry of the \\
rooster, it means he seeing \\
an angel. So ask Allah \\
for his bounties.)
\end{tabular}

The table above shows that the westerners tend to perceive the rooster in different ways to Middle Easterners, particularly Arabs. Only examples 2 and 3 from the table seem to have the same symbols in both eco-cultural systems whereas the following examples 4, 5, 6, 7 and 8 adopted by Arabs do not seem to have counterparts in the Western ecological value-system. This diversity of people's perceptions of the rooster tends to give rise to potential difficulties and problems in translating the word from an Arabic literary and/or religious context into an English literary and/or religious context as illustrated, for example, in the following line of poetry by Assarei Arrafaa (Note 4) describing and comparing the clarity and purity of wine with the clarity and purity of the eyes of a rooster.

\section{وصافيةٍ كعينِ الديكِ صِرفٍٍ. تُنتّي الثَاربينَ لها العقو لا}

A. It is as clear as the rooster's eyes it would make the drinkers lose their minds

B. The wine is so crystal clear it would make the drinkers lose their minds

C. It is so clear that it would make its drinkers lose their minds

Version A would not have a communicative impact on an English-speaking reader because their ecological perception of the rooster would not allow them to appreciate the simile found in the SL but version B would as their perception of clarity accepts crystal as a symbol of absolute clarity and purity. Crystal is a geo-ecological element used here to refer to the concept and perception of absolute clarity and purity. Therefore, the translator must not only be aware that there are different symbol systems in Arabic and English but also then decide whether to use the SL ecological system or that of the TL. In this paper, we call for an eco-cultural approach that would emphasize the SL and its culture as this would be more suitable to convey the exact ecological meaning, associations and cultural connotations of the term in question. This would also make the translation sound contextually, functionally and creatively 'novel and appropriate'.

\section{The Translation of Flora Ecological Terms}

As for the the term 'Flora', it refers to "the collective plant life that grows or once grew in a certain area or during a given time period" (Note 5). In other words, mountain plants/ trees are different from desert plants/trees due to differences in the eco-system and the environment in which they are grown or seen in naturally. Their impact on the people living in the areas they are found in, for example, tends to formulate people's perceptions, beliefs, customs and habits. That is why people's appreciation of certain plants or trees tends to vary depending on the region and the environment they belong to. An English person may not appreciate the value of a 'date palm tree' as much as an Arab from the Arabian Peninsula, and, likewise, an Arab may not appreciate the value of 'daffodils' as much as an English person.

Belonging to two different ecological systems, Arabic-English-Arabic flora translation tends to cause serious problems to translators in terms of capturing the ecological dimensions of the text in general and the ecological term in particular as illustrated below. 
Flora Example (4): The translation of 'floraness' in the term: 'Assidr/السدر/Assidr Tree/the Lote-Tree

'Assidr' tree is a specific Middle Eastern, heat resistant, mountainous and desert plant. This tree grows mainly in the Arabian Peninsula and particularly in Yemen where the climate is scorching hot and verdure is not abundant. To an Arab Muslim the term 'Assidr tree' or the 'Lote tree' has also specific feeling of environmental belonging, medical health associations and religious spiritual connotations. In such an eco-system where Assidr trees grow, the bee, for example, finds its own nectar and produces what is called 'Assidr honey' which is considered to be one of the healthiest natural medicines as mentioned in the following Quranic Verse: 16:69 and prophetic Hadeeth (Note 6):

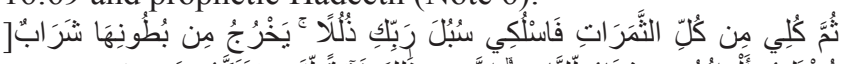

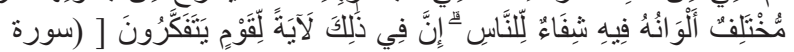
(النحل، أية 69

[And to eat of all the produce (of the earth), and follow the ways of Thy Lord made smooth: there issues from within their bodies a drink of varying colors, wherein is healing for men: verily in this is a Sign for those who give thought]. (S:16:A:69)

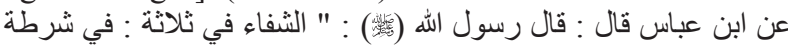

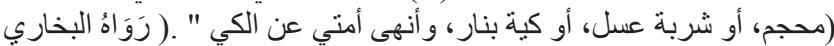

Ibn Abbas reported that the Prophet (㗪) said: "Healing can be done by three: Through mihjam cupping, the drink of honey or cauterizing with fire, and I forbid my people the act of cauterizing with fire. (Bukhari)

The religious and specifically spiritual connotations of 'Assidr tree' are positively mentioned in the Quran)Surah 56: Aya:28(:

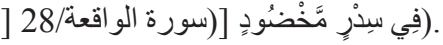

[The Companions of the Right Hand (They will be) among Lote trees without thorns] (S:56, A:28) and in the following Prophetic hadeeth:

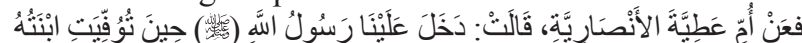

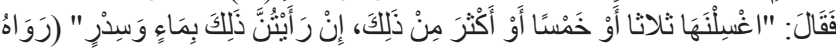

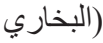

Um Atiyya Alansariyah reported that when his daughter died, the Messenger of Allah (能疑) entered upon us and said: "Bathe her three times, five times or even more with water and Sidr if you see appropriate". (Bukhari)

However, to a non-Muslim, be a Westerner or an Easterner, it is associated with 'the crown of thorns' placed on Christ's head before his crucifixion (Note 7). This also reflects the ecological relationship between this plant and its natural habitat in Palestine as well as the belief and perceptions of Christians all over the world.

This contrast in the beliefs and perceptions held by two different religious groups, Muslims and Non-Muslims, caused by two different ecological systems, one that exists in the Middle East and another that does not exist in Europe generally and Britain particularly, seems to cause serious problems in translating the ecological dimensions implied in the term assidr السدر which can be seen in the translation of the following line of poetry cited in Aljahiz (2006:121)

أناني نسيم السدر طيباً إلى الحمى. فذكرني نجداً فقطعني وجدا.

A. A Christ's Crown of Thorns breeze came home and reminded me of Najd which made me very nostalgic
B. Sweet Sidr breeze came home nicely bringing with it memories of Najd which made me nostalgic.

This line of poetry contains two ecological terms; a floral term assidr/ السدر and a geographical term Najd/نجد which would create two problems; one, how to translate the terms into English and two, how to make them perceivable by the Target Language readers whose eco-cultural system has neither a floral nor geographical counterpart to the SL terms. Version A above cannot be an appropriate effective translation of the original text because the translator used a literal approach in his translation and emphasised the target language eco-cultural and religious associations by using the term 'Christ's Crown of Thorns'. Version B used a transliteration approach which would still cause some difficulty for the TL reader to appreciate the positive connotation of the Lote-Ssidr tree breeze. Moreover, in both versions A and B the term $\mathrm{Najd}$ نجد was only transliterated depriving it from its eco-geographical significance by not modifying it. For the Arabs in general and Saudis in particular, this central part of Saudi Arabia has a well-loved huge hill called Najd hill where Lote-Ssidr trees normally grow. To be able to convey the exact eco-cultural truth value of the flora term and geographical term represented in Assidr and Najd respectively, a SL and culture emphasis strategy needs to be applied where a descriptive equivalent consisting of a couplet, triplet, quartile or even five modifiers could be used to achieve a more accurate and satisfying translation of the above example as follows:

\section{Prose Vesrion}

The loved and blessed-Lote-Sidr-tree-sweet breeze hit home

with memories of Najd great hill which made me very nostalgic.

Poetry Version

And as a scent so sweet came and hit home

From the loved blessed-Lote-Sidr-tree

Memories of Najd great hill flooded in

With nostalgia's bittersweet to come visit me.

Flora Example (5): The translation of 'floraness' in the term: 'alhabbah Assawdaa/الحبة السوداء/Black Seed/or habbat albarakah/حبة البركة/the Blessed Seed

"Alhabbah assawdaa" is an aromatic plant which mainly grows in West Asia and Mediterranean regions but does not generally grow in Europe. This difference in its ecological habitat tends to reflect differences in its denotative and connotative meanings to people living in two different environments, belonging to two different religions and having two different mindsets in terms of their perception and attitude towards this plant and its seeds. For Muslims in general, and Arabs in particular, this 'seed' means a "saline-free and fresh soil, a fruit used as spice, a cure for all diseases except death and it is a source of blessings".

When it comes to the translation of such term from Arabic into English, the translation of the 'floraness' in "alhabbah assawdaa' becomes quite complicated if not impossible. This is due to the fact that this term carries with it a denotative meaning of a certain type of 'spice with distinguished taste and smell used in food' as well as connotative meanings 
implied in its medical and health uses as well as religious and spiritual associations which are illustrated below.

Before giving our contextualized example of "alhabbah assawdaa" for translational analysis, it is relevant to mention here the common names or equivalents normally used in English for "alhabbah Assudaa" which are as follows: "nigella sativa' as its scientific name, black cumin, black caraway, fennel flower, nutmeg flower and Roman coriander. This diversity in its equivalence tends to make the translation of the term in the following two examples quite difficult and challenging:

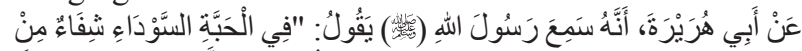

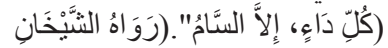

If we wanted to translate it into any of the suggested English equivalents mentioned above, the translation would not be accurate because the denotative and connotative meanings for alhabbah assawdaa are different from those of black cumin, black caraway, fennel flower, nutmeg flower and Roman coriander. The following is an example of how different they could be and consequently how they reflect differences in their ecological habitat, health or religious connotations.

Abu Hurairah reported that he heard the Messenger of Allah (站喽) saying:

A. "The Black cumin has a cure for all diseases except death." (Bukhari \& Muslim)

B. "The Black caraway a cure for all diseases except death." (Bukhari \& Muslim)

C. "The fennel flower has a cure for all diseases except death." (Bukhari \& Muslim)

D. "The nutmeg flower has a cure for all diseases except death.” (Bukhari \& Muslim)

E. "The Roman coriander has a cure for all diseases except death." (Bukhari \& Muslim)

The above examples show how serious a mistake in translating an ecological term in a Prophetic hadeeth can be. It is not only a matter of translatability but rather of ability to render an ecological concept that would carry its specific eco-cultural dimensions. Therefore, I suggest the following alternative translation where not only the SL and eco-culture are emphasised but also the accuracy, clarity and religiosity of the hadeeth achieved especially with the addition of the italic word 'blessed':

Abu Hurairah reported that he heard the Messenger of Allah (矣) saying: “The 'Blessed' Black Seed has a cure for all diseases except death." (Bukhari \& Muslim)

Another example is in the repetition of alhabbah assawdaa in the following two lines of poetry by Muhammad bin Hajar Almakki (cited in Almadani,1969) describing the mole on his beloved's cheek as a clear and glowing 'habbah assawdaa' and asking to kiss it so that he could be healed of exhaustion as healing is found in 'habbah assawdaa'.

$$
\begin{aligned}
& \text { (محمد بن حجر المكي: } \\
& \text { يا ذا الذي من خاله حبة سوداء في الخد الثديد الصفاً }
\end{aligned}
$$

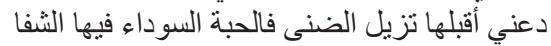

If the translator wanted to use any or all of the English equivalents mentioned above, they would be either over or under translating the term which is loaded with denotative, connotative and referential meanings. Therefore, I sug- gest the following alternative translation where the SL and eco-culture are emphasised and poetic communicative purpose and impact achieved with the use of the italic words as an eco-cultural equivalent in English:

Oh you who have upon your cheek a mole,

A seed of deep black, like the rocks of coal,

Let me in tire take from you a kiss so pure,

For in the blessed black seed there be found a cure.

Flora Example (6): The translation of 'floraness' in the term: 'alajwa date العجوة/Date Palm Tree

There are many types of palm tree which grow in various different places and are characterised by their specific ecological characteristics and purposes. Some grow in tropical areas and others in desert, some are used for landscaping while others for commercial uses as in for decorating indoor buildings or for oil production. However, not all types are edible ones. Only coconut and date palm trees are. The latter is the topic of our discussion in this section.

Unlike any other type of palm tree, the Arabian date palm tree tends to stand out as ecologically unique. It grows in abundance in the Middle East in general, and the Arabian Peninsula in particular, and is used as shelter from the scorching heat by desert travellers. What makes the so-called desert's jewel tree so special is not only its environmental connections but also its sentimental value to humans. It is so sacred that it is mentioned in the Quran: (S:50:A10):

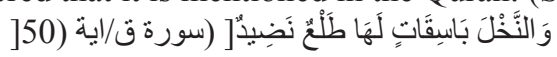

[And tall (and stately) palm-trees, with shoots of fruitstalks, piled one over another] (S:50/A10)

The fruit of this tree, the date, is truly what makes it extraordinary and the tree is so loved that it currently stands as the symbol of Saudi national pride. Its religiosity formulates the perception of Muslims in general and Arabs in particular all over the world. There are many health and spiritual uses of its fruit that cannot be overlooked and, as a result, dates form a principle elements in the diet of Arabs. It also has countless eco-cultural associations and connotations which is why Arabic Literature in general tends to be abundant with examples where a date palm tree is mentioned or its fruit praised. This can be seen in the following prophetic hadeeth:

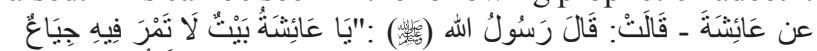

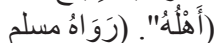

Aishah reported that the Messenger of Allah (絽) said: " The home without dates is a home with hungry people" (Muslim)

When it comes to translating ecologically loaded terms, as in the case with the examples above, there is a complex problem you meet. Although there are date palm trees in environments other than that of the Arabian Peninsula, translat-

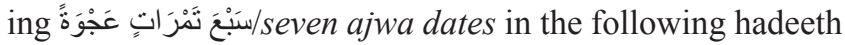
gives the translator not only semantic, communicative equivalence problems but also issues with finding the ecological equivalence loaded with its being a sacred desert fruit that has its religiosity, spirituality and canonicity in the minds and hearts of the Muslims and Arabs alike:

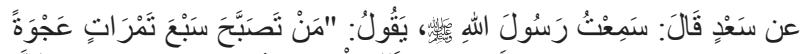

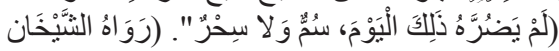

For a non-Muslim English speaking person, which of the following translations would be most appropriate in 
achieving the accuracy of meaning, clarity of expression, communicative effect and stylistic features of the hadeeth as a whole along with the spiritual experience that a reader should be able to enjoy:

Saed reported that he heard the Messenger of Allah (能) saying:

A. "He who eats seven dates in the morning will not be harmed by poison or magic during the day." (Bukhari \& Muslim)

B. "He who eats seven Arabian dates in the morning will not be harmed by poison or magic during the day." (Bukhari \& Muslim)

C. "He who eats seven Ajwa dates in the morning will not be harmed by poison or magic during the day." (Bukhari \& Muslim)

D. "He who eats seven blessed Ajwa dates in the morning will not be harmed by poison or magic during the day." (Bukhari \& Muslim)

E. "He who eats seven prophetically recommended Ajwa dates in the morning will not be harmed by poison or magic during the day." (Bukhari \& Mus$\lim )$

Looking at the above translations of the same Arabic text, we can see that A is a simple straight forward translation where the translator only used two words, 'a number and a noun', as in seven dates. This translation is void of any ecological connotation because it could refer to any variety of dates anywhere in the world and is also undertranslated by missing out on the translation of the word 'Ajwa'.

Translation B indicates that it is Arabian dates talked of but is a translation void of religiosity and spirituality because Arabian dates could refer to dates from anywhere in the Arabian Peninsula or even in the Arab world. This is why it cannot be an appropriate translation.

Three native speakers chose $\mathrm{C}$ as the most effective translation because it singles out the ecologically loaded term which is Ajwa, a variety of dates that mainly grows in Al-Madinah Almunawarah where the prophet (丵) is buried. However, they stated that they could not experience the ecological, religious and spiritual attachment to this variety of dates because they were non-Muslim and had no idea about the status of Al-Madinah Almunawarah in the hearts of Muslims. This is quite understandable considering their ecological and religious backgrounds.

Version D was rated second best as it gives a better understanding of the variety of dates than examples A, B and $\mathrm{E}$ and indicates its ecological association as well as religious and spiritual connotations. The readers could also experience the communicative impact caused by the word blessed, although this is an added word to boost such impact.

Version E was rated as the least effective translation although it explains all the ecological and cultural dimensions of the term. This is due to the fact that it cannot be considered a translation of the text in terms of accuracy. It is quite an over-translation which is not allowed religiously simply because it is a hadeeth of the prophet (站). However, if we wanted to emphasise the source language and its eco-cultural value system, then it would be a fine translation even if it sounded slightly foriegn.

Thus, in order of appropriateness, the above versions were ordered by three native speakers as follows: C, D, A, $\mathrm{B}$, and $\mathrm{E}$. This is a good example of how complex it can be to translate ecological terms in general and the term Ajwa date in particular.

\section{The Translation of Eco-Geographical Terms}

Geographical regions tend to vary and differ in terms of climate and landscape. The Middle Eastern geographical region in general, and the Arabian Peninsula in particular, for example, are characterised with certain geographical features that are in complete contrast with those of Europe and the United Kingdom in particular. The former tend to have hot and sometimes scorching summers with desert-like landscapes whereas the latter have quite the opposite with a climate that often ranges between cold and freezing over vast areas of green landscape.

These geographical regional features tend to also shape people's identity, personality and perceptions of the world around them. Mountains, hills, dunes, winds and storms are just a few examples of the eco-cultural system with which we feel strongly attached to. This can be abundantly seen, for instance, in literary texts and religious scripts which is our main focus of attention here.

Furthermore, this stark contrast between two eco-geographically different regions is bound to cause serious problems and difficulties in translating eco-geographical specific terms such as mountains, landscapes, winds and storms etc. as illustrated below

Eco-Geographical Example (7): The translation of 'Geographicalness' in the term: 'Jabal Uhud جبل أحد/Uhud Mountain

One of the most famous mountains among Muslims all over the world is the so-called 'Jabal Uhud جبل أحد Uhud Mountain. This mountain is considered to be one of the most well-known sites in the biography of the Prophet and Islam-ic history, overlooking the city of Madinah Almunawarah from the north about three and a half miles away from it. Mountain Uhud is associated with the famous battle that oc-curred in the third year of Hijra, namely the battle in which the polytheists won over the Muslims in the second round; because of the violation of the orders of the Prophet Mu-hammad (罂).

What makes the relationship between Muslims and this mountain unique and strong is the fact that this mountain includes a graveyard which has in it seventy buried Sahabi/ companions martyred during the Battle of Uhud, including the martyrs of Hamza bin Abdulmuttalib, the uncle of the Messenger of Allah (絽) and Abdullah bin Jahsh who were both buried in one grave. Another emotional dimension attached to this mountain is clearly manifested in the following two Prophetic Hadeeths:

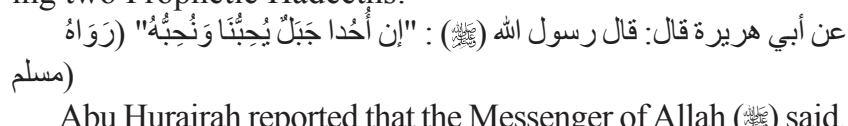

Abu Hurairah reported that the Messenger of Allah (絽) saic
"Uhud is a mountain that loves us and we love it." (Muslim) 


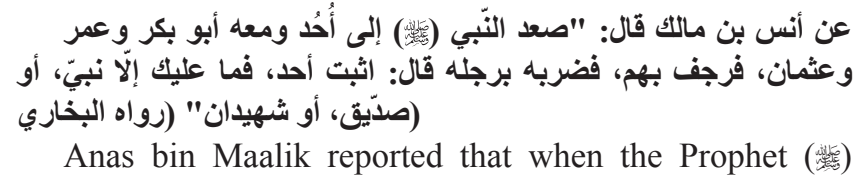
climbed Uhud Mountain accompanied by Abu Bakr, Omar and Othman, it shook underneath them, then the Prophet (能) stomped it with his foot and said, "Stay still Uhud. Only a Prophet or a trustworthy or two martyrs standing on you." (Bukhar)

Again, when it comes to translating such eco-geographical terms, problems arise in conveying the exact contextual meaning along with its eco-geographical associations and cultural and religious connotations. Let us look at the following example and see what kind of difficulty the translator encounters in translating these few poetic lines by Muhammad Almubaraki (Note 8) into English:

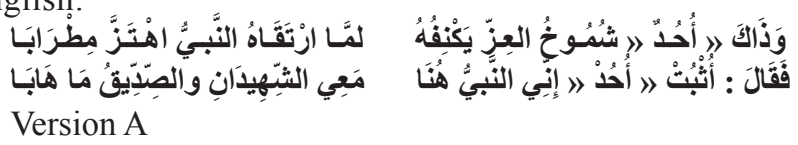

This is Uhud covered with greatness shook happily when the Prophet climbed it

He Said then "stay still Uhud, I am the Prophet with two martyrs and the Trustworthy not to be afraid

Version B

Mountain Uhud, symbol of greatness, shook out of happiness when the Prophet climbed it.

Said he "stay still, Uhud" I am the Prophet and with me two martyrs and a trustworthy be afraid not.

Version A of the translation of the above poetic lines seems to lack not only linguistic cohesion, coherence and stylistic rigour but also eco-geographical reference and significance.

Version B, however, seems to be a slightly better translation than Version A in terms of its linguistic cohesion and coherence achieving an approximate equivalence of the translation of the above poetic lines. It also identifies Uhud as a mountain which is a positive move in translation. It is, however, not good enough as it still lacks poetic stylistic features and any eco-geographical or historical reference and significance of the term Jabal Uhud/Uhud Mountain.

I, therefore, suggest the following Version $\mathrm{C}$ as an alternative translation where SL and eco-geographical features along with the historical associations, religious connotations and spiritual touches of the term are emphasised and poetic communicative purpose and impact achieved with the use of the italic words as an eco-geographical equivalent in English:

Version C

Cloaked with height and pride, there Uhud mountain stood

And at the Prophet climbing it, the mountain shook with joy fierce and clear

Then he said still yourself Uhud,

I am the Prophet with two martyrs and trustworthy siddiq do not fear.

Eco-Geographical Example (8): The translation of 'Geographicalness' in the term: 'Maqbarat Albaqee'مقبرة البقيع/(8)

\section{Albaqee' Graveyard}

What makes 'Albaqee' graveyard stand out as an eco-geographical historical landmark is not only its location, being adjacent to the Prophet's Mosque in the Eastern part of Al-Madinah Almunawarah, but also its holy spirit as it was reported that the Prophet (䗾) said that he had been ordered by Allah to make this piece of land a graveyard after he had migrated to it. It was also reported that more than ten thousand of the Prophet's companions, including a number of his own family members, martyrs of Uhud Battle and some martyrs of Badr Battle, were buried in it.

All these eco-geographical, historical, cultural, religious and spiritual features characterising this unique piece of land tend to give serious problems and difficulties in translating the term 'Maqbarati Albaqee'مقبرة البقيع/Albaqee' graveyard. So, which of the following possible versions of translation is the most appropriate in terms of accuracy, clarity, naturalness, communicative purpose and style while achieving a high degree of approximate equivalence to the original text:

A. Maqbarati Albaqee

B. Albaqee' cemetery

C. Albaqee' graveyard

D. Almadinah Almunawarah Baqee' graveyard

E. Almadinah Almunawarah Baqee' holy graveyard

Version A is simply transliteration and not clear enough while in Version B, the word cemetery is not appropriate because it does not indicate the religiosity of the place. It could be any place made for burying dead people. Version D seems to give some indication about the geographical status of the place being in Al-Madinah Almunawarah where the Prophet (能镜) is buried, but still does not necessarily have the religious/holy connotations found in version $\mathrm{E}$.

Now, if we want to achieve complete eco-geographical, historical, cultural, religious and spiritual equivalence in the translation of the above term, we could use version $\mathrm{F}$ below where the SL and eco-geographical features of the term are emphasised and religious and spiritual communicative purpose and impact achieved with the use of six nouns as modifiers of the word graveyard in English:

F. Al-Madinah Almunawarah-Prophet-10,000 companions-Baqee'- holy graveyard.

\section{CONCLUSIONS AND RECOMMENDATIONS}

Based on the brief discussion and analysis of the examples mentioned above, we can conclude that translating literary and religious Arabic Ecological terms into English in general tends to give rise to problems and difficulties in three ecological areas: Fauna, Flora and eco-geography specified by Newmark (1988). These problems and difficulties are due to differences in the eco-systems of the languages and cultures of Arabic and English. The former seems to have, for example, used in its literary and religious heritage different types of animals, trees, plants and landscapes to express their own views, perceptions, beliefs and feelings in a different manner from those used by the latter. The lack of eco-cultural counterparts in English makes translating ecological terms quite challenging if not impossible. 
More specifically, the problems and difficulties of translating Arabic ecological terms into English seem to have manifested at both conceptual and contextual levels. In other words, the Arabic fauna, flora and eco-geographical terms such as camel, Sider and Uhud mountain respectively seem to have shaped the Muslims and Arab's literary and religious perceptions and personal daily life in a manner not easy to transfer to the English readers whose perceptions of these ecological features could be either non-existent or based on false information because they are either not found in their ecological surroundings or, if found, have different ecological dimensions in terms of denotations and connotations and historical, and religious associations.

In addition to the solutions and alternative translations suggested at the end of each example given, the translator of Arabic ecological terms could also consider using:

a) a foreignising ecological approach to translation where he/she as a translator should emphasise the transfer of the Source Language's ecological system as well as the cultural and historical denotations and connotations of the ecological term in question to the English reader even if the resulting translation sounded slightly foreign (see Venuti, L, 1999 for foreignisation and domestication approaches in translation).

b) a descriptive equivalent consisting of a couplet, triplet, quartile or even five/six modifiers to turn the ecological term neutralized in the target language as used in the following:

AlMadinah Almunawarah-Prophet-10,000 companionsBaqee'- holy graveyard.

c) An eco-based mechanism to identify potential ecological problems and difficulties in the translation of Arabic Fauna, Flora and geographically featured terms into English and suggest solutions for such problems and difficulties.

As for those who are interested in carrying out further research in this field, they could investigate the translation problems of other ecological terms in different contexts and could also apply an ecological approach to investigating the problems of translating English ecological terms into other languages.

\section{ENDNOTES}

1. This is a name given to the bird which comes out from a weak and immature egg of a falcon; it results in a weak, dependent, and cowardly falcon that cannot hunt for himself.

2. http://www.whats-your-sign.com/symbol-meanings-ofthe-rooster.html

3. https://helloenglish.com/translate/english-hindi-dictionary/meaning-of-crow-in-Hindi

4. http://www.alwarraq.com

5. ahttps://www.conserve-energy-future.com/what-are-flora-and-fauna.php

6. Throughout this article, Abdullah Yousef Ali's (1990) English Translation of the Meanings of the Holy Quran was used and as for the Prophetic Hadeeths, the Arabic Versions of both Saheeh al-Bukhari (1998) and Saheeh Mus$\lim$ (1998) were used. (see the list of refernces above)
7. https://www.britannica.com/plant/Christs-thorn

8. http://www.al-madina.com/article/218705

\section{REFERENCES}

Ali, A.Y. (1990). The Holy Quran: English Translation of the Meanings and Commentary, AL-Madinah Al-Munawarah, King Fahd Holy Quran Printing Complex.

Abdul-Raof, H. (2005). "Cultural Aspects in Quran Translation”, in Long, Lynne (ed.) Translation and Religion, Topics in Translation, Multilingual Matters LTD.

Aljahiz, A. B. (2006) Kitaab Alhaywan (the Book of Merits and Demerits), AlMaktabah Alassrya, Beirut, Lebanon.

Aljahiz, A.B. (2008) Kitaab Alhaywan(the Book of the Animal), Alkitaab AlArabi Publishing House, Beirut, Lebanon.

Almadani, A. A. (1969) Anwar Arrabee'fee anwa' arrabee' (the Lights of Spring in the Kinds of Spring), Anamaan Publishing House, Iraq.

Al-Shabab, O.S. (2008). Linguistic and Cultural Translation in the Translations of the Holy Quran into European Languages. In Scientific Journal of King Faisal University, Vol.9, Issue No. 2

Ghazala, H. (2014) Translation as Problems and Solution: A Textbook for University Students and Trainee Translators, Konooz Al-Marifa for Printing \& Publishing, Jeddah, Saudi Arabia.

Halimah, A.M. (2014) “Translation of the Holy Quran: A Call for Standardization". Advances in Language \& Literary Studies, 5(1), 122-133.

Halimah, A.M. (2017) "Translation of Prophetic Hadeeths: Divine Challenges", European Journal of English Language \& Literature Studies, European Centre for Research, Training and Development (ECRTD), United Kingdom. Vol.5, No.10, pp.1-18.

Hodges, Karen E. (2008). Defining the Problem: Terminology and Progress in Ecology, Frontiers in Ecology and the Environment Journal, 6(1),35-42. http:// onlinelibrary.wiley.com/doi/10.1890/060108/full (Accessed on 1.12.17)

Nida, E. (1945) Linguistics and Ethnology in Translation-Problems, WORD, 1:2, 194-208, DOI: $10.1080 / 00437956.1945 .11659254$, by Routledge (Accessed on 1.12.17)

Nida, Eugene A. (1975/2001) Language, Culture, and Translating, Shanghai Foreign Language Education Press.

Newmark, P. (1988) A Textbook of Translation, Prentice Hall International.

Saheeh al-Bukhari (1998) International Idea Home, Riyadh, Saudi Arabia.

Saheeh M. (1998) International Idea Home, Riyadh, Saudi Arabia.

Vinokurov, A., Geller, D., \& Martin, T. (2007). Translation as an Ecological Tool for Instrumental Development, International Journal of Quantitative Methods.

Wormhoudt, A. (1978) Translation of Diwan al-Mu- 
tanabbi, published by William Penn College, Oskaloosa, Iowa, USA.

Zakumilina, M.N \& Lutfullina, G.F (2013). Structural approach in translating ecological terms of engineering protection, Interactive Collaborative Learning, International Conference on 25-27 Sept. 2013. http:// ieexplore.ieee.org/xpls/icp.jsp?arnumber $=644545$ (Retrieved 1.12.17) 